\title{
DOSSIÊ: INTERNACIONALIZAÇÃO DA EDUCAÇÃO SUPERIOR
}

\section{Apresentação}

\author{
$\diamond$
}

A educação superior nas últimas décadas vem sendo marcada pela complexidade da constituição de seu ethos. Abarcada pela globalização, com uma expansão acentuada em seus constitutivos - estudantes, professores, instituições, agências, etc. - e apoiada no desenvolvimento das tecnologias de informação, a educação superior se volta à internacionalização como solução para a busca da qualidade e da relevância.

É nesse cenário que a internacionalização da educação superior constrói-se como um conceito-chave neste século, deslocando-se de uma posição periférica a uma posição central e imbricada a uma noção positiva de qualidade. Como campo científico (BOURDIEU), é interdisciplinar, sendo apropriada por diferentes áreas de conhecimento, tais como relações internacionais, linguística, história e, em especial, educação e administração. Essa abrangência traz complexidade ao conceito de internacionalização da educação superior. No século passado, estava voltada, prioritariamente, à investigação e à produção do conhecimento, que via de regra ocorre em universidades e institutos de pesquisa, ou seja, estava em um campo restrito a poucos e com domínio de países desenvolvidos. Seu foco era a liberdade acadêmica e a autonomia do pesquisador e de seus parceiros, hoje constitutivos em redes para a construção da internacionalização. Já neste século, além da função pesquisa, a internacionalização tem como ponto principal o ensino e, dessa maneira, amplia seu espetro às instituições de educação pós-secundária de uma forma geral. Essa amplitude traz consigo discussões de fundo: a internacionalização atende à concepção de educação superior como serviço ou como bem público? Constitui-se em um grande negócio ou busca a integração solidária e o desenvolvimento mundial sustentável?

O conceito de internacionalização adotado implica também a consideração de diferentes dimensões decisórias: o global/regional, o nacional e o institucional. Todos eles imbricados e dependentes da soberania de um estado-nação, da centralização de políticas nacionais e também do tipo de instituição pós-secundária em que poderá ocorrer.

Na resenha do livro Global perspectives on higher education (2016), editado por Phillip Altbach, com 332 páginas, Rebecca Gavillet e Jennifer Zamora, da Universidade do Texas at Austin, buscam sintetizar a influência da internacionalização na educação superior do século XXI. Coordenado por um pesquisador com vasta produção sediada num centro de excelência em educação superior, o livro destaca a profunda relação com a globalização, conceituando-a como forças econômicas, políticas e sociais que impulsionam a educação superior do século XXI. No sentido de promover um maior envolvimento internacional, com impactos positivos, na medida em que as economias se ampliam; mas, paralelamente, também aspectos negativos, na medida e $\mathrm{m}$ que se aprofundam as disparidades econômicas e as desigualdades sociais.

Para entender a internacionalização da educação superior, a teoria dos campos de Pierre Bourdieu pode auxiliar. No artigo Circulação de ideias e internacionalização da educação superior, de Mario Luiz Neves de Azevedo (Universidade Estadual de Maringá), Afrânio Mendes Cattani e Ana Paula Hey, ambos da Universidade de São Paulo (USP), os autores discutem as perspectivas da internacionalização entre o sentido privatista, individualista e de formação para a permanência da supremacia dos dominantes e o sentido humanista, da solidariedade e da civilidade dos 
contra-hegemônicos. Apontam também os limites e as possibilidades de um campo internacional da educação superior.

Os estudos sobre internacionalização da educação superior refletem o momento de transição que caracteriza os contextos emergentes, aqui entendidos como configurações em construção na educação superior observadas em sociedades contemporâneas e que convivem em tensão com concepções preexistentes, refletoras de tendências históricas. Esses estudos, por um lado, são produzidos por e para uma realidade sócio-histórica dominante do global norte e que, mais recentemente, teve a valoração de estudos sobre a Ásia. Buscando uma análise crítica sobre essa produção, foram incluídos, especialmente, neste dossiê, os dois artigos a seguir apontados.

O artigo Internacionalização das universidades americanas: história, filosofia, prática e futuro, de Patricia Somers, Arinda Solis Rodriguez e Janet Rodriguez, (Universidade do Texas at Austin) e Marilia Morosini (CEES/PUCRS - Centro de Estudos em Educação Superior), detém-se sobre a internacionalização de universidades dos Estados Unidos. Aponta a história, apresentando modelos (clássico, satélite e cofundado) e exemplos e examinando a presença da internacionalização nos campi (ou câmpus) americanos. As autoras discutem os contextos emergentes eivados do novo nacionalismo e de outras questões políticas que afetam a internacionalização e o futuro do campo.

No artigo Internationalisation of higher education: some reflections on Russia and China, John Morgan, (Nottingham/Cardif University) e Alexandre Anselmo Guilherme (PUCRS) discutem as experiências da Rússia e da China, países companheiros do Brasil nos BRICS, no processo de internacionalização, e os possíveis impactos que podem ocorrer para o desenvolvimento dessas nações. Dado que a importância do ensino stuperior para um desenvolvimento equilibrado é algo agora amplamente reconhecido por organizações internacionais, como o Banco Mundial e a Unesco, bem como por governos, os autores investigam se mudanças passadas e atuais no sistema russo e chinês de educação superior incentivaram o desenvolvimento equilibrado nesses países.

Paralelamente ao domínio do campo pelos estudos do global norte, registram presença poucos estudos nos quais a equidade e a preservação da identidade local são princípios imprescindíveis. Esses estudos, via de regra, são oriundos de realidades constitutivas do global sul, compreendidas aqui como além de posições geográficas e marcadas por fortes contradições socioeconômicas. A perspectiva do global sul é que se buscou destacar neste dossiê - Internacionalização da educação superior -, especialmente com os artigos que se seguem.

Nesse entender, a internacionalização da educação superior latino-americana e caribenha é considerada no bojo de suas especificidades e limitações como um meio para o alcance da integração regional e internacional solidária. Além de ser uma forma de reduzir a diferença entre os países, desenvolvendo as capacidades próprias nacionais e regionais e consolidando a integração que preserva a diversidade cultural, na qual a equidade e o respeito à identidade local são princípios necessários.

$\mathrm{Na}$ discussão da agenda global para a internacionalização da educação superior, organismos internacionais têm ocupado um espaço importante. No artigo Vincular la internacionalización con las prioridades de desarrollo de las instituciones de educación superior: una urgencia inaplazable, de Sylvie Didou Aupetit (Centro de Investigación y de Estudios Avanzados del Instituto Politécnico Nacional - Cinvestav - México), a autora afirma que, apesar da expansão das atividades de internacionalização, estas não bastaram para atender aos objetivos da agenda de internacionalização definida pela Conferência Regional de Educação Superior (CRES), convocada em 2008 pela Unesco. Não se vincularam organicamente com missões centrais para as universidades latino-americanas, tais como a promoção da equidade ou da inovação para fins de desenvolvimento social e produtivo. $\mathrm{O}$ artigo analisa ainda os ganhos e os desafios identificados tanto pelo cumprimento dos objetivos da CRES como pela necessidade de reimplantar o processo de internacionalização e desenhar modelos externos, mas eficientes.

As conferências regionais/mundial de educação superior (CRES/CMES), coordenadas pela Unesco, embora não possuam um caráter determinante, pois a soberania dos estados-nação é vigente, vêm ocupando um espaço de forte influência na elaboração de políticas nacionais e institucionais. Neste ano de 2017, o movimento político-acadêmico para uma nova orientação da educação superior ocorre e se consagra na CRES2018, que será realizada em Córdoba e que se constitui em 
preparatório para a CMES2019, em Paris. Em recente evento da Unesco/Iesalc (2017), que reuniu reitores e redes da América Latina e do Caribe, foi proposta, em relação à internacionalização para um desenvolvimento sustentável, a consideração nas funções universitárias, de ensino, pesquisa e inovação, com uma perspectiva de integração solidária da região e de diálogo com a sociedade. A seguir, alguns pressupostos que identificam tal postura, entre outros:

- Definir y adoptar indicadores de producción autóctonos, con fuerte orientación a las necesidades de la región y en diálogo con la sociedad, teniendo en cuenta la pertinencia de la producción y las particularidades de la región;

- Maximizar un uso eficiente de los recursos, estímulo a la producción científica tecnológica e innovativa, y el desarrollo de vínculos fuertes con las demandas sociales;

- Creación de vínculos entre los sistemas de investigación, ciencia y tecnología con los de innovación;

- Desarrollar vinculación y transferencia tecnológico-social, entre otros con los sectores empresariales;

- Desarrollar cooperación para el desarrollo tecnológico y la innovación;

- Compartir experiencias entre los actores tanto local como regionalmente, y desarrollar cooperación regional en CTI, desplegando agendas regionales de CTI, tanto como programas regionales de CTI;

- Implementar políticas de francas acciones para la integración de la educación superior para América Latina y el Caribe, promoviendo espacios de avances en la construcción del ENLACES;

- Prevenir y evitar la sustracción del talento humano efectuada a través de la emigración de personas con calificaciones académicas y profesionales implementando políticas públicas;

- Motivar la creación de una red de egresados con experiencia que hayan participado en programas de internacionalización;

- Fortalecer programas de cooperación solidaria con las IES de los países de América Latina y el Caribe, con atención a los países más de menor desarrollo;

- Fortalecer las iniciativas de cooperación sur-sur especialmente con países de África y pequeños países islas;

- Implementar el Convenio Regional de Convalidación de Estudio, Títulos y Diplomas de la Educación Superior en América Latina y el Caribe de 1974;

- Fortalecer la internacionalización solidaria de la educación superior de América Latina y el Caribe especialmente los ya existentes en la región;

- Promover la doble titulación regional e internacional, insertando carreras o programas cooperativos;

- Fortalecer programas de idiomas bajo un entendimiento multicultural (experiencia Brasily Paraguay);

- Ampliar los programas de profesionalización de docentes para la transmisión de conocimientos con visión internacional y competitiva;

- Impulsar la competitividad y movilidad de los graduados;

- Crear un banco de datos de programas desarrollados de altos estándar académicas y cientificas en el nivel de licenciatura, maestría y doctorados considerando la experiencia que se ha acumulado en IES de la región;

- Ampliar la implementación de políticas y acciones afirmativas de inclusión de género, etnias y grupos culturales diversos, de personas en condición de discapacidad, privadas de la libertad o que vivan en lugares alejados de los centros urbanos, personas con escasos recursos, migrantes, refugiados y otras poblaciones en condición de vulnerabilidad, buscando siempre su permanencia.

O Brasil considera a educação superior como responsabilidade do Estado, e suas políticas, gestão e avaliação são prerrogativas do governo central. Levando em consideração tal premissa, nesse entender, o país foi analisado numa perspectiva de políticas nacionais e de reflexos em casos institucionais. 
No artigo Políticas de internacionalização da educação superior: o contexto brasileiro, escrito por Olgaíses Maués e Robson dos Santos Bastos (Universidade Federal do Pará - UFBA), aos autores analisam algumas das políticas brasileiras de internacionalização que envolvem a mobilidade estudantil e de docentes, com o fito de desvendar a perspectiva da mercantilização do saber, aumentando, assim, a concorrência entre os países e o fomento da sociedade do conhecimento. Os autores identificam os principais vetores dos programas, das ações e das estratégias definidas pelos governos, verificando as motivações de sua instituição e o conceito de internacionalização que as perpassa.

A internacionalização como critério de qualidade da educação superior é marcante no Brasil. As pesquisas realizadas têm deixado clara essa relação, tanto na perspectiva da pós-graduação como também da graduação.

Assim, o artigo Internacionalização da educação superior e indicadores do Sinaes: de qual qualidade estamos falando?, escrito por José Vieira de Sousa (Universidade de Brasília - UNB), revela que a internacionalização tem ganhado centralidade nos debates sobre a qualidade das instituições de educação superior (IES). E, ao invés de acontecer espontaneamente, precisa ser estimulada por políticas institucionais. $\mathrm{O}$ autor investiga as estratégias de internacionalização adotadas por cinco universidades federais apontadas nos indicadores de qualidade do Sistema Nacional de Avaliação da Educação Superior (Sinaes), em 2014. Os resultados comprovam, por um lado, a complexidade do conceito de internacionalização da educação superior e as estratégias adotadas pelas IESs; e, por outro, a demanda de metas globais articuladas às diferentes formas de sua participação no processo.

A importância do professor e de seu processo de formação tem sido um dos pontos-chave quando se discute a qualidade da educação superior. Um estudo acerca dos contextos emergentes nos cursos de licenciatura no Brasil: em destaque a internacionalização, escrito por Marilene Dalla Corte (Universidade Federal de Santa Maria - UFSM), identifica a presença de contextos emergentes durante o processo de formação do professorado em cursos de licenciatura. Esses contextos se caracterizam por expansão e diversificação da educação superior, interlocução da educação básica e superior, níveis constitutivos do sistema de educação do país, da diversidade e, em especial, da internacionalização, entendida como desafio aos cursos de licenciatura. Tais considerações são decorrentes de uma pesquisa do estado do conhecimento, realizada na Biblioteca Digital do Instituto Brasileiro de Informação em Ciência e Tecnologia (IBICT), no período de 2012 a 2016.

Seja no global norte ou no global sul, este último com mais força, a mobilidade/ intercâmbio acadêmico, o crossborder, marca o conceito de internacionalização. Entretanto, esse tipo de internacionalização, que poderia ser denominado de tradicional, é dependente da riqueza do país e/ou da solidariedade e de interesses dos mais ricos em relação aos mais pobres. No Brasil, a taxa de intercâmbio internacional é muito baixa: dos 397.611 docentes (INEP/MEC, 2017), somente $2 \%$ dos graduandos que realizaram o Enade (exame obrigatório para todos que se graduarão em um determinado ano), em 2013, tiveram uma experiência internacional institucionalizada durante o seu curso (MOROSINI e GRIBOSKI, 2015), e somente 33\% dos professores de programas de pós-graduação tiveram uma capacitação internacional. É também de registrar que predomina uma mobilidade passiva, com baixas taxas de atração de profissionais internacionais, já que "... o processo de internacionalização nas instituições brasileiras não é mais incipiente" (CAPES, 2017, p. 46).

Diante do cenário de não atingimento das metas de internacionalização via mobilidade, estão sendo propostos outros tipos de internacionalização que se complementem. Podem ser citadas a internacionalização at home (IaH), ou doméstica, a internacionalização do currículo (IoC) e também a internacionalização comprehensive ou integral. A internacionalização em casa possibilita que a instituição universitária ocupe um espaço significativo na sociedade, que não seja dependente da mobilidade. Um espaço que possibilite o acesso à internacionalização por diferentes camadas sociais latino-americanas e que contribuam para o desenvolvimento mundial sustentável, marcado pela convivência democrática, pelo respeito, pela solidariedade e pela cooperação para uma cidadania socialmente responsável.

No artigo Internationalisation at home: internationalising the university experience of staff and students, escrito por Sue Robson (New Castle University), a autora argumenta que, se as 
universidades querem ser verdadeiramente "internacionais", elas devem começar "em casa". Para tanto, faz-se necessário realizar uma revisão das atuais práticas de internacionalização, envolvendo educadores, estudantes, desenvolvimento de pessoal, unidades de serviço profissional e aqueles em posições de liderança, no sentido de ajudar as instituições de educação superior a se orientarem em direção a valores básicos e abordagem ética desse tema.

Ao finalizar, é importante destacar que as realidades estão em permanente mudança, e o embate entre internacionalização/globalização, embora esse último conceito ainda seja dominante, apresenta tensões com perspectivas de nacionalismo e regionalização, entre outras. Nesta década, discutem-se conceitos de desglobalização e/ou enfraquecimento da globalização, com o surgimento de um novo nacionalismo, expresso, entre outros, pela exigência de proteção aos cidadãos natos e de imposição de barreiras a pessoas de outras nacionalidades. Para o campo da internacionalização da educação superior, as posturas assumidas pelos Estados Unidos e pelo Reino Unido são importantes, pois congregam a maioria das redes acadêmicas do atlântico norte, expressão da competência científica.

No campo da internacionalização, o futuro faz-nos levantar inúmeras arguições. Ambicionou-se abordar tais questões neste dossiê e pensar propostas possíveis com o distanciamento de conceitos dogmáticos e idealistas de internacionalização e globalização e a compreensão nos seus significados, como meio para um fim.

MARILIA MOROSINI

Organizadora

\section{REFERÊNCIAS}

MOROSINI, M.; GRIBOSKI, C. Estudo nacional sobre internacionalização e permanência de concluintes da graduação no Brasil. In: INTERNATIONAL CONGRESS OF THE LATIN AMERICAN STUDIES ASSOCIATION - LASA2015: Precariedades, exclusiones, emergencias, 33., 2015, Puerto Rico. Puerto Rico: San Juan, 2015. p. 1-13. Disponível em: <https://lasa.international.pitt.edu/auth/prot/congress-papers/Past/ lasa2015/files/ 19047.pdf>.

CAPES. A internacionalização na universidade brasileira: resultados do questionário aplicado pela Capes. Brasília: Capes/DRI, outubro 2017.

INSTITUTO NACIONAL DE ESTUDOS E PESQUISAS EDUCACIONAIS ANÍSIO TEIXEIRA. Sinopse estatística da Educação Superior 2016. Brasília: Inep/MEC, 2017. Disponível em: <http://www:inep.gov.br>. Acesso em: 12 nov. 2017.

UNESCO/IESALC (2017). Declaración de Porto Alegre. VIII Encuentro de RedES universitarias y consejos de rectores de América Latina y el Caribe: hacia la CRES 2018. La educación superior regional de cara a los objetivos de desarrollo sostenible. Porto Alegre, 28 y 29 de agosto de 2017. 